\title{
Dose-response effect of sodium cromoglycate pressurised aerosol in exercise induced asthma
}

\author{
WM TULLETT, KM TAN, RT WALL, KR PATEL
}

From the Department of Respiratory Medicine, Western Infirmary, Glasgow, and the Pharmaceutical Division, Fisons PLC, Loughborough, Leicestershire

ABSTRACT The effects of 2,10 , and $20 \mathrm{mg}$ of sodium cromoglycate delivered by aerosol were compared with those of placebo in a double blind study in 11 patients with extrinsic and exercise induced asthma. The effect of nebulised sodium cromoglycate delivered through a Wright nebuliser (estimated dose $12 \mathrm{mg}$ ) was also studied. Patients exercised on a treadmill for six to eight minutes at submaximal work loads on five days, 30 minutes after inhaling placebo or sodium cromoglycate. The $\mathrm{FEV}_{1}$ was recorded before treatment, before exercise, and up to 30 minutes after exercise. Mean baseline values of $\mathrm{FEV}_{1}$ before and after placebo or sodium cromoglycate did not differ significantly on the five days. After exercise the mean (SEM) maximal percentage fall in $\mathrm{FEV}_{1}$ after placebo; $12 \mathrm{mg}$ sodium cromoglycate nebuliser solution; and 2, 10, and $20 \mathrm{mg}$ sodium cromoglycate aerosol were $31 \cdot 1(3 \cdot 8) ; 9 \cdot 4(2 \cdot 1)$; and $19 \cdot 4(4 \cdot 6), 13 \cdot 7(3 \cdot 5)$, and 9.4 (1.9). Sodium cromoglycate inhibited exercise induced asthma at all doses used; the protective effect of the aerosol increased from 2 to $20 \mathrm{mg}$. The protective effect of $20 \mathrm{mg}$ sodium cromoglycate aerosol was similar to that seen with $12 \mathrm{mg}$ nebulised solution. Our results suggest that the effect of sodium cromoglycate aerosol in exercise induced asthma is dose related.

The inhibitory effect of sodium cromoglycate in exercise induced asthma is well documented. Some patients, however, find the spinhaler difficult to use and humid climates may produce clumping of the hygroscopic sodium cromoglycate powder.' To overcome these problems a new formulation of sodium cromoglycate has been developed for use in a pressurised aerosol, delivering $1 \mathrm{mg}$ per actuation. Two milligrams of sodium cromoglycate given by aerosol gave protection against exercise induced asthma similar to $20 \mathrm{mg}$ sodium cromoglycate powder in two studies, ${ }^{23}$ but less protection in asthmatic children in a third. ${ }^{4}$ In previous studies we showed that the inhibitory effect and duration of action of sodium cromoglycate in exercise induced asthma is dose related when given by nebulisation. ${ }^{56}$ The recent development of a pressurised aerosol delivering $5 \mathrm{mg}$ of sodium cromoglycate per actuation allowed us to examine the dose-response effect of the aerosol in exercise induced asthma. We have compared the effect of 2,10 , and $20 \mathrm{mg}$ sodium

Address for reprint requests: Dr KR Patel, Department of Respiratory Medicine, Western Infirmary, Glasgow G11 6NT.

Accepted 10 August 1984 cromoglycate aerosol with that of placebo in a double blind study in 11 patients.

\section{Methods}

We studied 11 patients, aged 19-51 (mean 32) years with extrinsic bronchial asthma and positive responses to skinprick tests for common allergens. All patients had previously been shown to have both exercise induced asthma, with a fall in $\mathrm{FEV}_{1}$ of more than $20 \%$ after exercise, and at least $40 \%$ protection of their exercise induced asthma with $1 \mathrm{ml}(10$ $\mathrm{mg}$ ) nebulised sodium cromoglycate. Patients taking oral or aerosol corticosteroids, antihistamines, and anticholinergic drugs were excluded; six patients having regular treatment with sodium cromoglycate were included. Bronchodilator drugs were stopped for 12 hours and sodium cromoglycate for two days before each study. All patients gave informed consent to being studied and the protocol was approved by the hospital ethics committee. Forced expiratory volume in one second $\left(\mathrm{FEV}_{1}\right)$ was measured with a dry wedge spirometer, the best of three attempts being used for analysis.

Exercise testing consisted of steady state running on an inclined treadmill $\left(10^{\circ}\right)$ for six to eight 
minutes. The speed was adjusted so that the patient's heart rate at the end of the exercise study was 160 beats per minute. The same setting and duration were used for each test in any one patient. A series of five tests on each patient was completed within 14 days. The temperature on the study days varied from $20^{\circ}$ to $22^{\circ} \mathrm{C}$ and the relative humidity from $40 \%$ to $60 \%$. The effect of inhaling sodium cromoglycate nebuliser solution $(10 \mathrm{~g} / \mathrm{l})$ by tidal breathing through a Wright's nebuliser driven by compresed air at a flow rate of $9 \mathrm{l} / \mathrm{min}^{-1}$ was studied first. The estimated dose of sodium cromoglycate nebulised was $12 \mathrm{mg}$. The second part of the study was carried out in a randomised $(4 \times 4$ Latin square) double blind fashion with placebo and two metered dose aerosols delivering $1 \mathrm{mg}$ and $5 \mathrm{mg}$ sodium cromoglycate per actuation.

Each subject inhaled four puffs from two identical inhalers (two puffs from each) 30 minutes before exercise. The four puffs contained 2,10 , and $20 \mathrm{mg}$ sodium cromoglycate and placebo. The FEV, was recorded 30 minutes after the inhalation before exercise and at $2,5,10,15$, and 30 minutes after exercise. The $\mathrm{FEV}_{1}$ response to exercise was expressed as the maximal fall in $\mathrm{FEV}_{1}$ from the postdrug baseline. Responses to each drug were compared by an analysis of variance and Student's paired $t$ test.
Results

There was no significant difference between the mean baseline value of $F E V_{1}$ before and after treatment on the five study days (table 1). After exercise the mean (SEM) maximum percentage falls in $\mathrm{FEV}_{1}$ after placebo; sodium cromoglycate nebuliser solution; and 2,10 , and $20 \mathrm{mg}$ of sodium cromoglycate aerosols were $31.1(3.8) ; 9.4(2.1)$; and $19.4(4.6), 13.7(3.5)$, and $9.4(1.9)$ respectively (table 2). The exercise induced fall in $\mathrm{FEV}_{1}$ was inhibited by all the doses of sodium cromoglycate used in the study ( $p<0.01$ for $2 \mathrm{mg}$ and $\mathrm{p}<0.001$ for 10 and $20 \mathrm{mg}$ ). The inhibitory effect as measured by fall in $\mathrm{FEV}_{1}$ after exercise was significantly greater after $10 \mathrm{mg}$ and $20 \mathrm{mg}$ than after $2 \mathrm{mg}$ sodium cromoglycate ( $<<0.05$; figs 1 and 2$)$. Twenty milligrams of sodium cromoglycate aerosol had the greatest protective effect, though this was not significantly different from $10 \mathrm{mg}$. The protective effect of nebulised sodium cromoglycate (estimated dose $12 \mathrm{mg}$ ) was similar to that of $20 \mathrm{mg}$ of the aerosol.

\section{Discussion}

Exercise induced bronchoconstriction is a well recognised phenomenon in asthma and, although the

Table 1 Baseline values of FEV, before and after administration of placebo and sodium cromoglycate (SCG) in 11 patients

\begin{tabular}{|c|c|c|c|c|c|c|c|c|c|c|}
\hline & \multicolumn{2}{|l|}{ Placebo } & \multirow{2}{*}{\multicolumn{2}{|c|}{$\frac{\text { Nebulised SCG }}{12 \mathrm{mg}}$}} & \multicolumn{6}{|c|}{ SCG aerosol } \\
\hline & \multirow[b]{2}{*}{ Before } & \multirow[b]{2}{*}{ After } & & & \multicolumn{2}{|l|}{$2 \mathrm{mg}$} & \multicolumn{2}{|l|}{$10 \mathrm{mg}$} & \multicolumn{2}{|l|}{$20 \mathrm{mg}$} \\
\hline & & & Before & After & Before & After & Before & After & Before & After \\
\hline $\begin{array}{l}\text { Mean } \\
\text { SEM }\end{array}$ & $\begin{array}{l}3.20 \\
0.29\end{array}$ & $\begin{array}{l}3 \cdot 20 \\
0 \cdot 30\end{array}$ & $\begin{array}{l}3 \cdot 22 \\
0.31\end{array}$ & $\begin{array}{l}3.27 \\
0.31\end{array}$ & $\begin{array}{l}3 \cdot 20 \\
0 \cdot 32\end{array}$ & $\begin{array}{l}3 \cdot 21 \\
0.32\end{array}$ & $\begin{array}{l}3.17 \\
0.31\end{array}$ & $\begin{array}{l}3 \cdot 14 \\
0.30\end{array}$ & $\begin{array}{l}3 \cdot 24 \\
0.32\end{array}$ & $\begin{array}{l}3.25 \\
0.30\end{array}$ \\
\hline
\end{tabular}

Table 2 Maximal percentage fall after exercise with placebo, sodium cromoglycate nebuliser solution $12 \mathrm{mg}$, and aerosol 2,10 , and $20 \mathrm{mg}$ sodium cromoglycate (SCG) in 11 patients

\begin{tabular}{|c|c|c|c|c|c|c|c|}
\hline \multirow{2}{*}{$\begin{array}{l}\text { Patient } \\
\text { No }\end{array}$} & \multirow[t]{2}{*}{ Age } & \multirow[t]{2}{*}{ Sex } & \multirow[t]{2}{*}{ Placebo } & \multirow{2}{*}{$\begin{array}{l}\text { Nebulised } \\
\text { SCG } \\
(10 \mathrm{~g} / \mathrm{l})\end{array}$} & \multicolumn{3}{|c|}{ SCG aerosol } \\
\hline & & & & & $2 m g$ & $10 \mathrm{mg}$ & $20 \mathrm{mg}$ \\
\hline $\begin{array}{l}1 \\
2 \\
3 \\
4 \\
5 \\
6 \\
7 \\
8 \\
9 \\
10 \\
11 \\
\text { Mean } \\
\text { SEM }\end{array}$ & $\begin{array}{l}23 \\
26 \\
45 \\
26 \\
28 \\
51 \\
22 \\
36 \\
42 \\
37 \\
19 \\
32\end{array}$ & $\begin{array}{l}\mathbf{F} \\
\mathbf{M} \\
\mathbf{M} \\
\mathbf{F} \\
\mathbf{F} \\
\mathbf{F} \\
\mathbf{M} \\
\mathbf{F} \\
\mathbf{F} \\
\mathbf{F} \\
\mathbf{M}\end{array}$ & $\begin{array}{r}18.4 \\
39.1 \\
43.1 \\
23 \cdot 1 \\
30.2 \\
46.2 \\
19.1 \\
52.4 \\
18.3 \\
18.5 \\
32.9 \\
31 \cdot 1 \\
3.8\end{array}$ & $\begin{array}{r}10 \cdot 7 \\
14 \cdot 4 \\
23 \cdot 5 \\
2 \cdot 6 \\
12 \cdot 1 \\
8 \cdot 1 \\
16 \cdot 4 \\
4 \cdot 3 \\
3 \cdot 8 \\
6 \cdot 8 \\
1 \cdot 1 \\
9 \cdot 4 \\
2 \cdot 1\end{array}$ & $\begin{array}{r}17 \cdot 2 \\
11.7 \\
24.6 \\
5.8 \\
37.8 \\
34.2 \\
7.4 \\
50.5 \\
12.5 \\
7.6 \\
4.6 \\
19.4 \\
4.6\end{array}$ & $\begin{array}{r}13.4 \\
12.9 \\
14.0 \\
2.3 \\
13.0 \\
24.0 \\
2.4 \\
43.8 \\
6.0 \\
9.4 \\
9.4 \\
13.7 \\
3.5\end{array}$ & $\begin{array}{r}8.7 \\
20.7 \\
0.4 \\
3.9 \\
12.7 \\
9.0 \\
14 \cdot 5 \\
17 \cdot 3 \\
5.5 \\
7 \cdot 3 \\
3.9 \\
9.4 \\
1.9\end{array}$ \\
\hline \multicolumn{4}{|c|}{$\begin{array}{l}\text { p, comparison with placebo } \\
\text { p, comparison with } 2 \text { mg aerosol }\end{array}$} & $0 \cdot 01$ & 0.01 & $\begin{array}{l}0.001 \\
0.05\end{array}$ & $\begin{array}{l}0.001 \\
0.05\end{array}$ \\
\hline
\end{tabular}


$\%$ CHANGE FEV $_{1}$

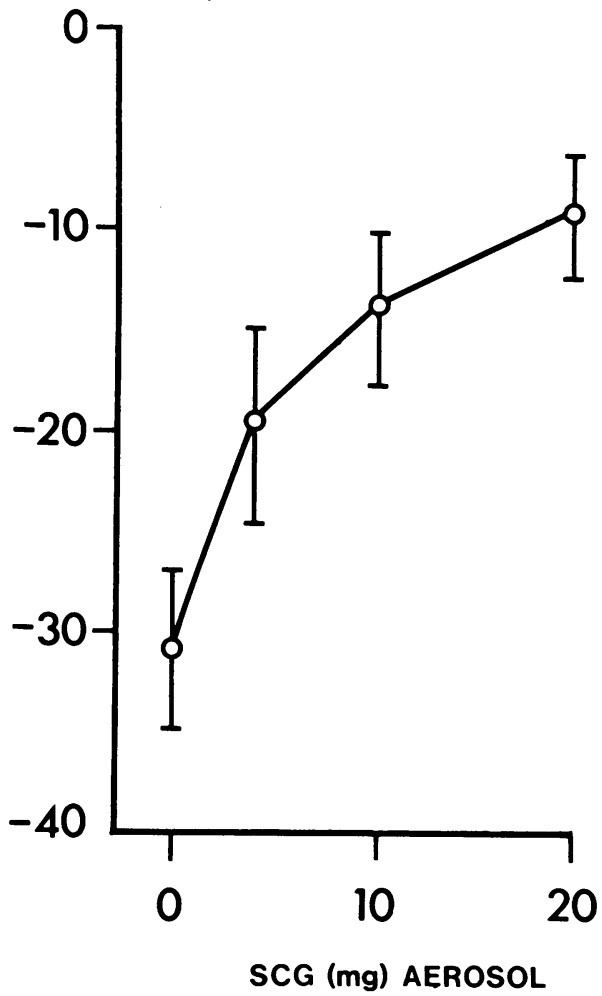

Fig 1 Mean (SEM) maximal percentage change in FEV , after exercise with placebo and increasing doses of sodium cromoglycate aerosol.

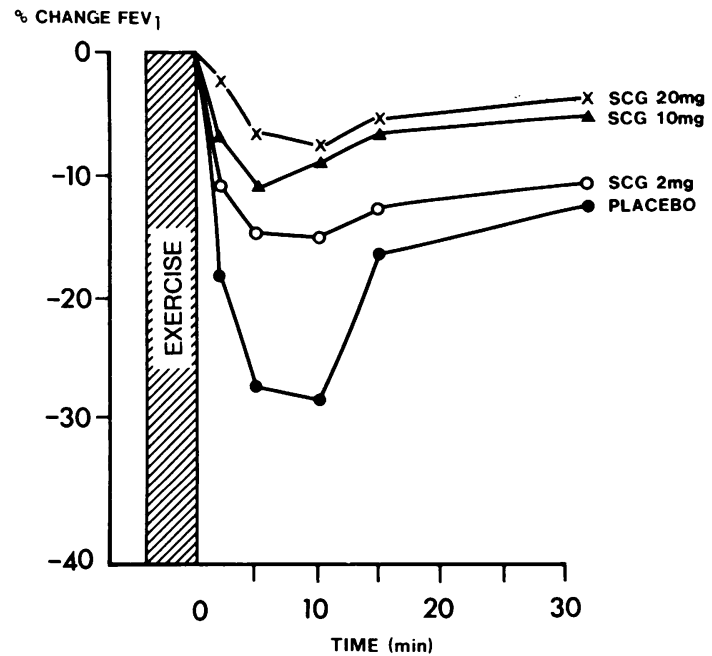

Fig 2 Mean percentage change in FEV (from baseline after administration of drug) over 30 minutes after exercise with different doses of sodium cromoglycate aerosol. exact mechanism of its pathogenesis remains unclear, it provides a relatively safe method for assessing the effect of various drugs. Sodium cromoglycate has been shown to inhibit exercise induced asthma in most patients. Some, however, find it difficult to use the spinhaler device, and the high affinity of sodium cromoglycate powder for water may produce clumping of the powder in humid climates,' with loss of efficacy. In these circumstances the aerosol formulation of sodium cromoglycate is more suitable, and most patients find it convenient to use. Although the $1 \mathrm{mg}$ dose delivered by the first aerosol is considerably smaller than the $20 \mathrm{mg}$ delivered by the spinhaler, $2 \mathrm{mg}$ given by aerosol has been shown to be effective both in clinical trials ${ }^{7-9}$ and in exercise induced asthma. ${ }^{23}$ In the present study sodium cromoglycate pressurised aerosol inhibited the fall in $\mathrm{FEV}_{1}$ at all the doses used and the protective effect increased from 2 to $20 \mathrm{mg}$ (fig 1). The inhibitory effect of $20 \mathrm{mg}$ sodium cromoglycate aerosol was comparable to that of $12 \mathrm{mg}$ nebulised sodium cromoglycate delivered through a Wright's nebuliser. The aerosol sodium cromoglycate did not produce bronchodilatation as reported with the nebulised solution. ${ }^{510}$ The results of the present study are in accord with the dose-response effect of nebulised sodium cromoglycate found in our previous study of exercise induced asthma. ${ }^{5}$ In contrast, Latimer and colleagues ${ }^{11}$ did not observe a dose-related protection with sodium cromoglycate aerosol against bronchoconstriction induced by airway cooling in their patients. The mechanisms of bronchoconstriction induced by exercise and airway cooling remain controversial, ${ }^{12}{ }^{13}$ and the differences in results between the two studies may be related to the different methods of provoking bronchoconstriction.

The optimal dosage of sodium cromoglycate for prophylaxis and prevention of exercise asthma varied between patients in our study. The $5 \mathrm{mg}$ dose aerosol of sodium cromoglycate allows greater flexibility in adjusting dosage and frequency of administration. The aerosol has a further advantage over the dry powder formulation in that the particle size is unaffected by atmospheric humidity.

We thank Mrs Rita Jack for technical assistance and Mrs J Peter for typing the manuscript. The study was supported by Fisons PLC, Pharmaceutical Division.

\section{References}

1 Cox JSG, Woodward GD, McCrone WC. Solid state chemistry of cromolyn sodium. J Pharm Sci 1971;60: 1458-65.

2 Schoeffel RE, Anderson SD, Lindsay DA. Sodium cromoglycate as a pressurised aerosol (VICROM) in 
exercise-induced asthma. Aust $N \quad Z$ J Med 1983; 13: 157-61.

3 Bundgaard A, Bach-Mortensen N, Schmidt A. The effect of sodium cromoglycate delivered by spinhaler and by pressurized aerosol on exercise-induced asthma in children. Clin Allergy 1982;12:601-5.

4 Bar-Yishay E, Gur I, Levy M, Volozni D, Godfrey S. Duration of action of sodium cromoglycate on exercise-induced asthma: comparison of 2 formulations. Arch Dis Child 1983;58:624-7.

5 Patel KR, Berkin KE, Kerr JW. Dose-response study of sodium cromoglycate in exercise-induced asthma. Thorax 1982;37:663-6.

6 Patel KR, Kerr JW. The dose-duration effect of sodium cromoglycate in exercise-induced asthma. Clin Allergy 1984;14:87-91.

7 So SY, Yu DYC. Sodium cromoglycate delivered by pressurised aerosol in the treatment of asthma. Clin Allergy 1981;11:479-82.

8 Lal S, Malhotra SM, Gribben MD. Comparison of sodium cromoglycate pressurized aerosol and powder in the treatment of asthma. Clin Allergy 1982;12: 197-201.

9 Geller-Bernstein C, Levin S. Sodium cromoglycate pressurised aerosol in childhood asthma. Curr Ther Res 1983;34:345-9.

10 Chung JTN, Jones RS. Bronchodilator effect of sodium cromoglycate and its clinical implications. $\mathrm{Br} \mathrm{Med} \mathrm{J}$ 1979;ii: 1033-4.

11 Latimer KM, Roberts R, Morris MM, Hargreave FE. Inhibition by sodium cromoglycate of bronchoconstriction stimulated by respiratory heat loss: comparison of pressurised aerosol and powder. Thorax 1984;39:277-81.

12 Deal EC jun, Wasserman SI, Soter NA, Ingram RH jun, McFadden ER jun. Evaluation of role played by mediators of immediate hypersensitivity in exerciseinduced asthma. J Clin Invest 1980;65:659-65.

13 Ben-Dov I, Bar-Yishay E, Godfrey S. Refractory period after exercise-induced asthma unexplained by respiratory heat loss. $A m$ Rev Respir Dis 1982;125:530-4. 